\title{
EL DIÁLOGO COMO MÉTODO
}

DIALOG AS METHOD

\section{Pilar Flores \\ Roberto Vega}

ISSN (imp): 1390-4825

ISSN (e): 2477-9199

Fecha de recepción: 04/01/19

Fecha de aceptación: 05/19/19 


\section{Resumen:}

Este artículo se refiere al intercambio de ideas que se viene dando hace algunos años entre Pilar Flores y Roberto Vega; intercambio expresado en conversaciones, apuntes e imágenes que, eventualmente, se han convertido en textos. La escritura de estos textos ha construido pensamiento a partir de reflexiones que son sostenidas por ejes y elementos conceptuales que, a su vez, potencian el lenguaje de imágenes y permiten identificar las posibilidades de la creación. En este proceso, la escritura se convierte en la obra artística, entendida como un sistema complejo, que se nutre de conexiones inusuales, del cambio, de la inestabilidad; se construye desde la incertidumbre, la duda y la intuición.

\section{Palabras clave:}

conversaciones, escritura, diálogo, sistema, cambio, inestabilidad, incertidumbre, duda, intuición

\section{Abstract:}

This article refers to the exchange of ideas between Pilar Flores and Roberto Vega, this exchange is expressed in conversations, notes and images that have become texts. In them, thought has been built through reflections supported by pivotal ideas and conceptual elements that enhance the language of images and lead to identify the possibilities of artistic creation. In this process, writing has become the artwork, understood as a complex system, that feeds on unusual connections, change and instability, and which is built from uncertainty, doubt, and intuition.

\section{Key Words:}

conversations, writing, dialogue, system, change, instability, uncertainty, doubt, intuition

\section{Biografía de los autores:}

Pilar Flores (Quito, 1957). Ha realizado treinta exposiciones individuales en Europa y América del Sur. Entre 2015 y 2016 presentó la muestra antológica Aliento, en el Centro de Arte Contemporáneo, Quito. Su producción se ha construido desde espacios de colaboración y transdisciplinariedad, abarca obras que expanden los medios tradicionales e integran el espacio como elemento clave. Investiga prácticas antiguas de Oriente y su actualización en Occidente, articula procesos de creación en investigación artística, impulsa un diálogo muy fértil entre la práctica artística y la práctica docente. Es profesora de la Carrera de Artes Visuales, de la Pontificia Universidad Católica del Ecuador y es autora de varios libros. www.pilarflores.org tzununazul@hotmail.com

Roberto Vega (Quito, 1989). Ha exhibido su trabajo en Estados Unidos, Alemania, Espańa y Ecuador. A través de instalaciones o intervenciones para sitio específico, centra su investigación en las formas de habitar los espacios, en el tiempo y la memoria que éstos contienen. Es profesor de Fundamentos de Escultura en la Universidad San Francisco de Quito y es parte del equipo del Centro de Arte Contemporáneo de Quito.

www.robertovega.blog robertovegacornejo@gmail.com 
"El acto mágico consiste en ligar dos cosas que están distantes, en producir una chispa en el roce de dos heterogeneidades, en encontrar el lugar en el que se realiza una conexión inesperada. Como ya lo mostraba Giordano Bruno (De la magia, De los vínculos en general), la magia es el arte de producir vínculos y de allí su vocación política: se trata de un modo de pensar los modos en los que "estar juntos" en un espacio que, en última instancia, es el territorio que la propia conexión mágica construye”. ${ }^{1}$

En la práctica artística conjunta que desarrollamos, consideramos a nuestros diálogos como un método de creación. Este método nos ha llevado a experimentar escribiendo textos "a cuatro manos". Se trata de una serie de reflexiones verbales y gráficas "de ida y vuelta". Las preguntas que vamos a intentar responder en este artículo son ¡cómo la interlocución de dos artistas, de generaciones alejadas, aporta a su creación artística? ¿cómo registramos este proceso de interlocución?

Nuestras conversaciones empezaron en abril del 2016 con el objetivo de construir nuestros procesos artísticos desde estos diálogos. En primer lugar, desplegamos las imágenes que cada uno estaba trabajando y las preguntas que teníamos sobre ellas; no nos planteamos caminos cerrados ni un objetivo en común, sino que quisimos explorar a dónde nos llevaría lo que, individualmente, teníamos en ese momento. Consideramos que este intercambio podría potenciar nuestros viajes.

Estos diálogos empezaron a darse de manera permanente, con el compromiso de aportar "un ladrillo a la vez", sin imaginar todavía "la pared", ni con el cuestionamiento de para qué serviría ese "ladrillo". Cada uno de nosotros es parte de otra generación, es así que percibimos la realidad, la vida, y la creación de la obra, de maneras diferentes. A cada uno nos enriquecen experiencias distintas, sin embargo, creímos posible generar un espacio de encuentro y apostamos por un terreno neutral, a pesar de las distancias.

Estas conversaciones se dieron de varias maneras, alrededor de una mesa o inclusive en comunicaciones

1 Ulm, H. (2018). Reseńa: La imagen inquieta. Juan Downey y Raúl Ruiz en contrapunto de Fernando Pérez Villalón. Cuadernos de Arte $\mathrm{N}^{\circ}$ 22. pág. 101. Santiago de Chile: Escuela de Arte, Facultad de Artes Pontificia Universidad Católica de Chile. virtuales a distancia. ${ }^{2}$ Esta práctica de comunicación desbordó el proceso creativo para, muchas veces, detenerse en los temas que atraviesan la vida y la complejizan. En estos diálogos conectamos lo que nos estábamos preguntando en el trabajo artístico, con los retos que movilizan la experiencia del día a día.

Tres años después, estos encuentros y sus diálogos, nos han llevado a una construcción de pensamiento a través de varios escritos, que contribuyen a la construcción de elementos conceptuales que sostienen nuestras discusiones. Hemos escrito varios textos ${ }^{3}$ y hemos logrado identificar las dimensiones que nos preocupan; en este transcurso, nuestro lenguaje de imágenes se potencia al identificar las abstracciones del proceso artístico. Vislumbramos estos diálogos desde la creación artística, como una posibilidad de entrever sistemas sin bordes definidos y con configuraciones distintas. La fuerza de la escritura a dos voces está precisamente en que, lo dicho y lo escrito es escuchado de manera permanente, respondido y cuestionado simultáneamente. El otro artista se convierte en un espejo, que nos permite reconocernos, vernos y, a la vez, ver el mundo y situarnos en él. Así, en el proceso, la escritura se ha convertido en la obra artística.

En nuestras conversaciones, nos preguntamos acerca de las formas de comunicación que crean la fantasía de una conectividad total y una extrema exposición de la intimidad de las personas. ${ }^{4}$ Existe una aparente transparencia y una cercanía ficticia; pero al escarbar un poco, descubrimos que esta forma de comunicación da la ilusión de abarcarlo todo y tiene el peligro de la homogeneización que desdibuja particularidades $y$, al mismo tiempo, del rechazo a la alteridad y a la diversidad. Esta hiperconectividad confunde la referencia de la

2 Roberto Vega, entre septiembre de 2016 y mayo de 2018, estuvo estudiando una maestría en la School of Visual Arts de la ciudad de Nueva York.

3 Textos trabajados colectivamente (Pilar Flores y Roberto Vega): 1) texto curatorial de la exposición Bitácoras de Color (octubre 2018), publicado en la revista INDEX (revista \# 6 de la Carrera de Artes Visuales, PUCE). 2) Procesos inestables: aprendizaje y convivencia, texto inédito para las memorias del II Encuentro de Arte, Educación, Interculturalidad, CAV, llevado a cabo en octubre 2018. 3), Creación: movimiento y relación, texto inédito para el libro Pensar en Imágenes, proyecto Bitácoras de Color, de Pilar Flores. 4) Correspondencia, duda y mirada, introducción al libro pensar en Imágenes, proyecto Bitácoras de Color, de Pilar Flores. y 5) el presente texto: El Diálogo Como Método.

4 Fietta Jarque (2015, p. 76) comenta: "Vivimos en una época en la que se han borrado las fronteras de lo que se llamaba intimidad. Todo el mundo se exhibe mediante imágenes que recogen cualquier momento o circunstancia. Las más triviales y las memorables bajo el mismo rasero". 
motivación desde la cual construimos. Una de las maneras de responder a esta situación es a través de la noción de Byung-Chul Han quien, frente a "la resistencia de lo "otro", [que] perturba y retarda la lisa comunicación de lo igual" (A. 2018, p. 13) propone la ternura como una forma de resistencia que respeta lo diferente. Además, cree necesario "ejercitarse en la 'actitud de la distancia" " para acercarse al Otro aceptando "lo que no entendemos"; no es necesario que entendamos todo, que conozcamos todo, que desvelemos todo.

Así, nos propusimos un espacio de comunicación donde el diálogo, desde la ternura, es el núcleo. Acudimos a estas conversaciones con la confianza de que, en los cruces de ideas y preguntas, nos encontraríamos en nuestras diferencias. En este contexto, entendemos la ternura como Jacques Salomé la describe: "un arte de la comunicación, de la puesta en común, un arte de la relación que permite a cada uno ser más uno mismo" (1991, p. 41). Una de las formas que usamos para registrar las conversaciones, fueron apuntes e imágenes (Imágenes 1-5), las cuales nos sirvieron como mapas mentales para la escritura de textos cuyas reflexiones recogen el proceso del diálogo. Mediante el ejercicio de escritura, hemos profundizado en la complejidad de la búsqueda de sentido en los diversos aspectos de la vida. Nos afirmamos en esta relación vida-procesos artísticos desde el punto de vista de García Canclini (2013, p.22) quien nos dice que el arte atraviesa todos los espacios donde se desenvuelve el ser humano.

Entendemos el trabajo artístico como una entidad viviente y compleja. Anteriormente, hemos hecho referencia ${ }^{6}$ a la metáfora de los sistemas vivos, esta metáfora ha sido tomada de los jardines construidos como parte del proyecto "Bitácoras de Color", 7 que son "dinámico[s], cambiante[s] y depende[n] de sus constantes relaciones con el entorno" (Llamazares 2011, p. 278). De esta misma manera entendemos nuestro trabajo: el diálogo transformado en textos de reflexión crece y se complejiza de la misma manera que un jardín. Es un sistema vivo que se sostiene en la relación de sus partes.

5 R. Sennett, Respeto. Sobre la dignidad del hombre en un mundo sin igualdad. Barcelona: Anagrama, 2003. Citado por Byung-Chul Han (A. 2018, página 16).

6 En el texto citados en la nota al pie número 4.

7 Jardín urbano en el techo del taller de Pilar Flores, jardín de plantas nativas aledaño a las instalaciones de la Carrera de Artes Visuales PUCE y los jardines de lluvia construidos en la escuela del Buen Pastor y en el Centro de Arte Contemporáneo.
Byung-Chul Han define la complejidad de los sistemas vivos tomando en cuenta tres aspectos. Primero "la peculiaridad de lo viviente consiste en interrumpir la causa exterior transformándola y haciendo comenzar en sí algo nuevo". Segundo, "lo viviente reacciona con autonomía a lo externo" y, por último, "lo viviente nunca padece la causa externa de forma pasiva. Sin aportación ni decisión por parte de lo interior, la causa externa nunca llega a repercutir" (B. 2018, pág. 15). Asimismo, el autor anota que estos puntos también alumbran la complejidad de la vida espiritual.

En el sistema de escritura al que hacemos referencia, reconocemos ejes conceptuales que articulan las partes micro y macro de este proyecto, en total cuatro: a) el intercambio en la convivencia, b) el reconocimiento del sujeto, de su mirada y de sus preguntas, c) la diversidad, d) la apertura y e) la inestabilidad. Así, este ejercicio se constituye igual que un jardín, un aula de clases y un proceso de montaje, -todas, dimensiones del proyecto Bitácoras de Color ${ }^{8}$.

El proceso de escritura fue complejizándose mientras avanzamos, lo que nos permitió identificar sus ejes y definirlos. Ayudados por gráficos, construimos ensambles que nos permitieron nombrar, situar $y$ relacionar los modos de configuración y las partes de este sistema multidimensional. Similar a un sistema vivo, este proceso se nutre del cambio y se construye desde la incertidumbre, la duda y la intuición. Byung-Chul Han sostiene que, el exceso de información no lleva a la construcción de conocimiento, pues "la intuición [...] va más allá de la información disponible y sigue su propia lógica[...] tanto el pensamiento como la inspiración requieren un vacío" (A. 2018, p. 17).

Hemos puesto énfasis en la duda filosófica expresada en preguntas que están en movimiento, en viaje, que cambian, emergen, se desarrollan, desaparecen, se transforman y se problematizan. ¿Cómo una obra artística

8 En el proyecto "Bitácoras de color", una obra abierta que se encuentra en pleno desenvolvimiento y expansión, convergen la clase de pintura y los procesos creativos [tanto de la profesora como de los y las estudiantes]. En la intersección de estos elementos están conectados dos ensambles; el primero es el jardín como un sistema que manifiesta una red de relaciones y dimensiones diversas [...]. El segundo es la mesa [montaje] como objeto conceptual [...]. La mesa ovalada [...] fue parte de la exposición Bitácoras de color [...]. Ambos ensambles, mesa y jardín, están entrelazados por la mirada y las preguntas. Dentro del sistema, cada mirada condiciona las elecciones dentro de un campo de posibilidades amplio" (Flores y Vega, 2018). 
se materializa en un texto? ¿Cómo un texto abarca la complejidad de un proceso cuyo núcleo es visual? ¿Cómo desde el interior del sistema pensamos sobre el mismo?

"Me interesan aquellos delicados momentos en los que la mente entiende algo de pronto, la revelación, la epifanía. Esos momentos íntimos descritos por poetas y pintados por pintores en todas las culturas. Es algo que ilumina desde el interior y no desde el exterior" (2015, p. 188)

dice Sol Le Witt, en una entrevista que le realiza Fietta Jarque. Además, en 1969 escribió en relación a los procesos creativos: "los artistas (...) saltan hacia conclusiones que la lógica no puede alcanzar" (p. 255). Para nosotros ese "salto" es posible a través de la intuición.

El viaje, la navegación en el océano en la que los vientos redireccionan la barca, nos trasladan en horizontal, pero también nos sumergen. En la tierra tendríamos una sensación de estabilidad y cercanía; en el mar estamos a merced de los vientos. Nuestro proceso creativo es una estancia compartida en una barca, que se mueve, son las palabras las que sostienen esos encuentros.

Para la construcción de los elementos conceptuales que sostienen nuestras discusiones y la identificación de las dimensiones que nos preocupan, hemos escrito varios textos sostenidos por imágenes y mapas mentales que localizan las ideas y sus relaciones. A manera de conclusión creemos que la creación en el diálogo es posible en espacios que acogen lo nuevo, lo diferente y lo contradictorio; y está abierta a generar conexiones inusuales, en condiciones que no son estables. Encontramos que esta forma de creación es rizomática, nos acercamos a ella con la confianza de que "algo" va a emerger. No es pasiva frente a lo exterior; y su singularidad está en la manera de prestar atención al mundo y, desde él, influenciarlo y transformarlo.

La potencia del diálogo está en salir del espacio individual para encontrarse con Otro y reconocerlo en la particularidad de su mirada y de sus preguntas. Así, la creación en el diálogo se convierte en una entidad viviente y compleja en constante cambio.

\section{Referencias}

A. Byung-Chul Han. (2018). La sociedad de la transparencia. Barcelona: Herder.

B. Byung-Chul Han. (2018). Sobre el poder. Barcelona: Herder.

Flores, P. y Vega, R. (2018). Procesos inestables: aprendizaje y convivencia. Texto inédito para las memorias del II Encuentro de Arte, Educación, Interculturalidad, Carrera de Artes Visuales, PUCE, llevado a cabo en octubre 2018.

García Canclini, N. (2013). La sociedad sin relato. Madrid: Katz Editores.

Jarque, Fietta. (2015). Cómo piensan los artistas, México: Fondo de Cultura Económica

Llamazares, A. (2011). Del reloj a la flor de loto. Crisis contemporánea y cambio de paradigmas. Buenos Aires: Editorial Del Nuevo Extremo S.A.

Salomé, Jacques. (1991). Apprivoiser la tendresse. Ginebra: Etitions JOUVENCE.

Ulm, H. (2018). Reseña: La imagen inquieta. Juan Downey y Raúl Ruiz en contrapunto de Fernando Pérez Villalón. Cuadernos de Arte $\mathrm{N}^{\circ}$ 22. pp.101. Santiago de Chile: Escuela de Arte, Facultad de Artes Pontificia Universidad Católica de Chile. 




Figura 1. Mapa mental del proceso de escritura de textos. Pilar Flores, Roberto Vega. 2019.

Figura 2. Mapa mental del proceso de escritura de textos. Roberto Vega. 2019. 


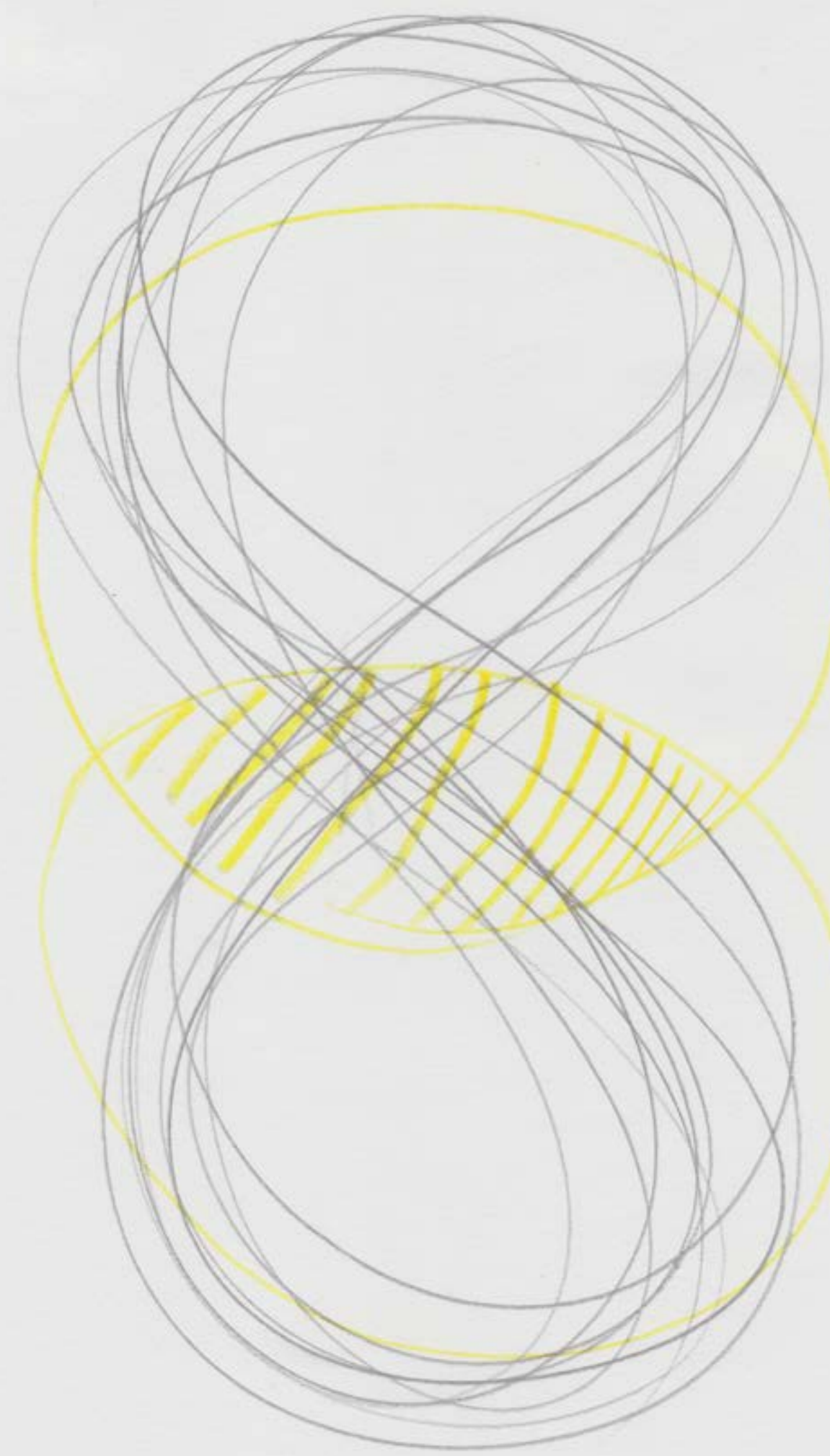

Figura 3. Apunte. Cinta de Moebius y espacio de encuentro.

Roberto Vega. 2019. 




Figura 4. Collage de Pilar Flores y Roberto Vega. 2019

Esquema Estáurico de Osvaldo Rodolfo Weilenmann Sola.

Fotocopia de Byung-Chul Han. (2018). La sociedad de la

transparencia. Barcelona: Herder. 


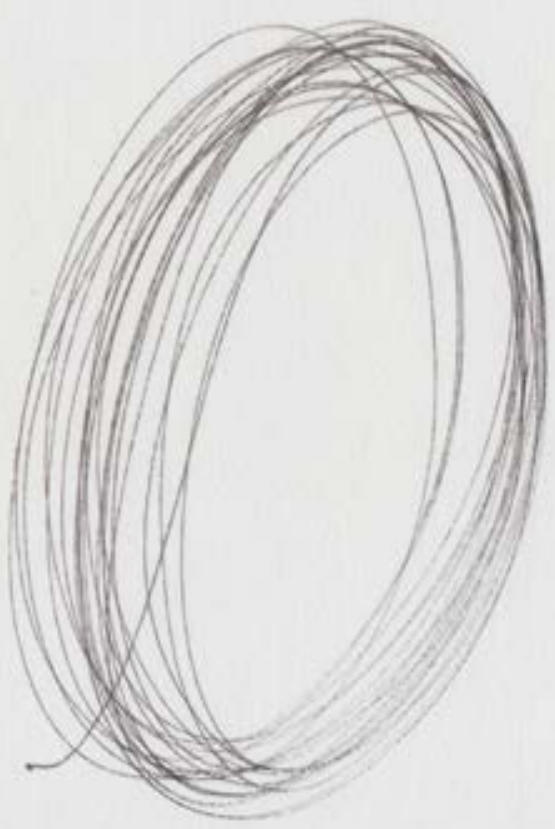

Figura 5. Apunte. Procesos abiertos. Roberto Vega. 2019.

174 